\title{
Schisandrae fructus enhances myogenic differentiation and inhibits atrophy through protein synthesis in human myotubes
}

This article was published in the following Dove Press journal:

International Journal of Nanomedicine

3I May 2016

Number of times this article has been viewed

\section{Cy Hyun Kim ${ }^{1,2, *}$ \\ Jin-Hong Shin ${ }^{1,3, *}$ \\ Sung Jun Hwang ${ }^{1,2}$ \\ Yung Hyun $\mathrm{Choi}^{4}$ \\ Dae-Seong Kim ${ }^{1,3}$ \\ Cheol Min Kim ${ }^{2,5}$}

'Research Institute of Convergence of Biomedical Science and Technology, Pusan National University Yangsan Hospital, Yangsan, ${ }^{2}$ Center for AntiAging Industry, Pusan National University, Busan, ${ }^{3}$ Department of Neurology, Pusan National University Yangsan Hospital, Yangsan, ${ }^{4}$ Department of Biochemistry, Dongeui University College of Korean Medicine, Busan, ${ }^{5}$ Department of Biomedical Informatics, Pusan National University School of Medicine, Yangsan, Republic of Korea

*These authors contributed equally to this work
Correspondence: Cheol Min Kim Center for Anti-Aging Industry, Pusan National University, 70-16, Eomgung-ro, Sasang-gu, Busan 47046, Republic of Korea

Tel +82 5I 3I5 74I6

Fax $+825 I 5838820$

Email kimcm@pusan.ac.kr

\begin{abstract}
Schisandrae fructus (SF) has recently been reported to increase skeletal muscle mass and inhibit atrophy in mice. We investigated the effect of SF extract on human myotube differentiation and its acting pathway. Various concentrations $(0.1-10 \mu \mathrm{g} / \mathrm{mL})$ of SF extract were applied on human skeletal muscle cells in vitro. Myotube area and fusion index were measured to quantify myotube differentiation. The maximum effect was observed at $0.5 \mu \mathrm{g} / \mathrm{mL}$ of SF extract, enhancing differentiation up to 1.4-fold in fusion index and 1.6-fold in myotube area at 8 days after induction of differentiation compared to control. Phosphorylation of eukaryotic translation initiation factor 4E-binding protein 1 and $70 \mathrm{kDa}$ ribosomal protein $\mathrm{S} 6$ kinase, which initiate translation as downstream of mammalian target of rapamycin pathway, was upregulated in early phases of differentiation after SF treatment. SF also attenuated dexamethasone-induced atrophy. In conclusion, we show that SF augments myogenic differentiation and attenuates atrophy by increasing protein synthesis through mammalian target of rapamycin/70 $\mathrm{kDa}$ ribosomal protein S6 kinase and eukaryotic translation initiation factor 4E-binding protein 1 signaling pathway in human myotubes. SF can be a useful natural dietary supplement in increasing skeletal muscle mass, especially in the aged with sarcopenia and the patients with disuse atrophy.
\end{abstract}

Keywords: Schisandrae fructus, mTOR signaling, human skeletal muscle cells, myotubes

\section{Introduction}

Sarcopenia, a syndrome of progressive and generalized loss of skeletal muscle mass and strength, poses a huge health care burden in the elderly. ${ }^{1-5}$ It has raised a great interest in the search for dietary ingredients that can help increase and maintain skeletal muscle mass. ${ }^{6-8}$ The dried Schisandrae fructus (SF) has been traditionally used in herbal medicine as the therapy for asthma, night sweats, insomnia, dry coughs, urinary disorders, involuntary ejaculation, poor memory, hyperacidity, chronic diarrhea, hepatitis, diabetes, etc. ${ }^{9-12}$ Previous studies on SF extract have reported various biological activities as antioxidant, antiviral, antitumor, and anti-inflammatory agent. ${ }^{13-18}$ Recently, SF has been shown to increase skeletal muscle mass and ameliorate atrophy in the mouse models of sciatic neurectomy and dexamethasone (DEX) treatment. ${ }^{19-24}$

Muscle hypertrophy is affected by balancing between protein synthesis and degradation. ${ }^{25}$ Several materials, such as leucine and ursolic acid, as well as exercise, have been known to induce skeletal muscle hypertrophy stimulating $\mathrm{v}$-akt murine thymoma viral oncogene homolog (Akt) or mammalian target of rapamycin (mTOR) signaling. ${ }^{26-32}$ Activation of mTOR generates upregulation of phosphorylated eukaryotic translation initiation factor 4E-binding protein 1 (p-4E-BP1) or phosphorylated $70 \mathrm{kDa}$ 
ribosomal protein S6 kinase (p-P70S6K). Those signals induce hypertrophy by enhancing translation of mRNAs.

On the other hand, inhibition of protein degradation (muscle proteolysis) has an important role for muscle hypertrophy and atrophy. ${ }^{25}$ Muscle RING finger 1 (MuRF1) is a key regulator for muscle proteolysis through ubiquitin-proteasome pathway. ${ }^{33-35}$ MuRF1 has increased in various atrophy conditions, including immobilization, denervation, hindlimb unloading, DEX treatment, and interleukin-1-induced cachexia. ${ }^{33-38}$ MuRF1 regulates muscle atrophy and attenuates muscle loss when deleted. ${ }^{39}$

Mechanism associated with myogenic differentiation by $\mathrm{SF}$ in human myotubes has not been well documented. We have assessed if SF could promote myogenic differentiation and which pathway it exploits in human skeletal muscle cells (HSkMCs).

According to our study, SF treatment increased protein synthesis through upregulation of mTOR/p-4E-BP1/p-P70S6K, while it did not reduce MuRF1 in human myotubes. Nevertheless, SF enhanced myogenic differentiation. In addition, SF attenuated atrophy caused by DEX through an increased protein synthesis. SF induced muscle protein synthesis but did not inhibit protein degradation in human myotubes.

\section{Materials and methods Materials}

SF extract was obtained from Research Center for AntiAging Technology Development (Busan Technopark, Busan, Korea). Extraction method of SF was indicated by previous research. ${ }^{15,21,22}$ SF was dissolved in dimethyl sulfoxide as a $20 \mathrm{mg} / \mathrm{mL}$ stock solution and diluted with medium prior to use. The following antibodies were purchased from the individual providers: mTOR (sc-136269), p-mTOR (\#2971), 4E-BP1 (\#9452), p-4E-BP1 (\#2855), P70S6K (\#2708), p-P70S6K (\#9234), myosin heavy chain 3 (MYH3, sc-53091), MuRF1 (ab172479), p-FOXO1 (\#9461), and GAPDH (MB001) antibodies were purchased from Cell Signaling (Danvers, MA, USA), Santa Cruz Biotechnology Inc. (Dallas, TX, USA), Bioworld (St Louis Park, MN, USA), and Abcam (Cambridge, UK). Secondary antibodies of antimouse (ADI-SAB-300-J) and antirabbit (ADI-SAB-100-J) were bought from Enzo Life Sciences (Farmingdale, NY, USA). Collagenase, dispase II, basic fibroblast growth factor, and DEX were bought from Sigma-Aldrich Co. (St Louis, MO, USA).

\section{Primary culture of HSkMCs}

We used HSkMCs cultured primarily from donated human muscle pieces. All donors gave their written informed consent and agreed to muscle sampling during their surgical procedures. This experiment was approved by Institutional Review
Board of Pusan National University Yangsan Hospital. The satellite cells were isolated from the muscle piece by collagenase/ dispase digestion and were grown in Ham's F10 medium (Thermo Fisher Scientific, Waltham, MA, USA) containing $20 \%$ fetal bovine serum, antibiotics (penicillin $50 \mathrm{U} / \mathrm{mL}$ and streptomycin $50 \mathrm{mg} / \mathrm{mL}$ ) and basic fibroblast growth factor (2.5 ng/mL). ${ }^{40,41}$ Muscle tissue was washed in Hank's balanced salt solution. Muscle $(\sim 250 \mathrm{mg})$ was then minced and placed in $1 \mathrm{~mL}$ of collagenase $(0.2 \%) /$ dispase II $(2.4 \mathrm{U} / \mathrm{mL})$ solution containing $8.3 \mathrm{mM} \mathrm{CaCl}_{2}$. Until completely digested, it was incubated at $37^{\circ} \mathrm{C}$ for 1 hour, being vortexed every 15 minutes. Digested muscle solution was filtered by a $100 \mu \mathrm{m}$ nylon cell strainer and diluted with complete medium. Strained solution was centrifuged for 5 minutes at $150 \times \mathrm{g}$, and the pellet was washed in $2 \mathrm{~mL}$ of complete Ham's F10 medium. Then, the pellets were resuspended and incubated in complete medium. Cells were seeded on gelatin-coated dish. Quality of human myoblast sample was checked with PAX3 (green, upper panel) and PAX7 (red, lower panel) stains (Figure S1). Growth medium was changed every 3 days. At confluence, HSkMCs were allowed to differentiate into myotubes. Differentiation of HSkMCs was induced by HSkMC differentiation medium (DM) (C-23061; PromoCell, Heidelberg, Germany).

\section{Fusion index and myotube area}

To observe differentiation efficiency, HSkMCs were seeded on 12-well plates $\left(2 \times 10^{4}\right.$ cells/well), and after 1 day, HSkMCs were treated with SF of $0.1 \mu \mathrm{g} / \mathrm{mL}, 0.5 \mu \mathrm{g} / \mathrm{mL}, 1 \mu \mathrm{g} / \mathrm{mL}, 5 \mu \mathrm{g} / \mathrm{mL}$, and $10 \mu \mathrm{g} / \mathrm{mL}$ in DM. Medium was changed to fresh DM with SF every 2 days. HSkMCs were photographed three times per group every 2 days for 8 days. Differentiation of HSkMCs was observed and photographed by phase-contrast microscopy (MCXI 600; MICROS, Vienna, Austria). Fusion index and myotube area were manually analyzed using ImageJ software. Fusion index is calculated as the ratio of the number of nuclei in fused myotubes per entire field. Myotube area is measured as the area covered by myotube in each photo. ${ }^{42,43}$

\section{Induction of atrophy}

To observe differentiation efficiency, HSkMCs were seeded on 6 -well plates $\left(1 \times 10^{5}\right.$ cells/well), and after 1 day, HSkMCs were treated with SF of $0.5 \mu \mathrm{g} / \mathrm{mL}$ in DM. Medium was changed to fresh DM with SF every 2 days. Two days after induction of differentiation, cells were incubated with $100 \mu \mathrm{M}$ DEX for 4 days to induce atrophy. ${ }^{44-47}$ Six days after the induction of differentiation, we took photos at three random spots in each group. For observing atrophy, we measured fusion index and myotube area. Cells were harvested with a Lipa buffer for protein extraction. 


\section{Immunofluorescent staining}

DM containing $0.5 \mu \mathrm{g} / \mathrm{mL}$ of SF was applied to the cells. After 6 days, cells were washed with phosphate buffered saline (PBS) and fixed by 4\% paraformaldehyde. Then, cells were permeabilized with PBS containing $0.25 \%$ Triton X-100 (PBST) for 25 minutes. These cells were incubated in 2\% BSA for 30 minutes and then with MYH3 antibodies for 2 hours. After washing with PBS, cells were incubated with fluorescent anti-mouse IgG antibody (Alexa 594; Thermo Fisher Scientific) for 1 hour. Nuclei were stained by Hoechst 33342 (DAPI, $1 \mu \mathrm{g} / \mathrm{mL}$ ) for 3 minutes. All antibodies were diluted in PBST containing 1\% BSA. These cells were mounted on a glass slide. The results were recorded using fluorescence microscopy (Eclipse 80i; Nikon Corporation, Tokyo, Japan).

\section{Western blot}

The cells were lyzed on ice using a Lipa buffer (GenDEPOT, Barker, TX, USA) for 30 minutes. Cell lysates were centrifuged at 13,000 rpm for 20 minutes at $4{ }^{\circ} \mathrm{C}$. The supernatant was collected, and the protein concentration was determined by a bicinchoninic acid protein assay kit. Equal amounts of protein $(40 \mu \mathrm{g})$ were separated using $4 \%-15 \%$ gradient sodium dodecyl sulfate polyacrylamide gel electrophoresis and then transferred to a polyvinylidene fluoride membrane (EMD Millipore, Billerica, MA, USA). The membrane was blocked with 5\% skim milk and incubated with p-mTOR, total mTOR, p-P70S6K (Thr389), P70S6K, p-4E-BP1, 4E-BP1, MuRF1, MYH, and GAPDH primary antibodies overnight at $4{ }^{\circ} \mathrm{C}$. Those membranes were washed with PBS containing $0.1 \%$ Tween 20 and incubated with a horseradish peroxidase-conjugated mouse or rabbit secondary antibodies for 1 hour at room temperature. The immunoblots were visualized by chemiluminescence horseradish peroxidase substrate (RPN 2235; GE Healthcare UK Ltd, Little Chalfont, UK).

\section{Statistical analysis}

All the experiments in this study were performed in triplicate. All data were shown as the mean \pm standard error of the mean. Statistical analysis was performed using analysis of variance followed by Tukey's honest significant difference post hoc test except for the Western blot results. Protein expression levels were analyzed using Student's $t$-test. The significance was taken as $P<0.05$.

\section{Results}

\section{SF induced differentiation in HSkMCs}

Proliferation effects of SF prior to differentiation test were investigated in HSkMCs. Various concentrations $(0.1 \mu \mathrm{g} / \mathrm{mL}$,
$0.5 \mu \mathrm{g} / \mathrm{mL}, 1 \mu \mathrm{g} / \mathrm{mL}, 5 \mu \mathrm{g} / \mathrm{mL}$, and $10 \mu \mathrm{g} / \mathrm{mL}$ ) of $\mathrm{SF}$ in growth medium were treated in a 12 -well plate 1 day after the seeding of $4 \times 10^{4}$ cells per well. At 2 days after SF treatment, HSkMCs were trypsinized to be counted. Proliferation efficiency has not shown significant difference compared with control (Figure 1A). HSkMCs were treated with SF of $0.1 \mu \mathrm{g} / \mathrm{mL}, 0.5 \mu \mathrm{g} / \mathrm{mL}, 1 \mu \mathrm{g} / \mathrm{mL}, 5 \mu \mathrm{g} / \mathrm{mL}$, and $10 \mu \mathrm{g} / \mathrm{mL}$ in DM. Differentiation of HSkMCs was observed and photographed by phase-contrast microscopy (MCXI 600; MICROS) every 2 days. For observing differentiation efficiency, fusion index and myotube area were analyzed. As shown in Figure 1B and C, overall fusion index and myotube area were the highest at 6 days. SF treatment of $0.5 \mu \mathrm{g} / \mathrm{mL}$ resulted in significantly higher fusion index at 6 days after differentiation, which tended to remain high until day 8 (Figure 1B). Myotube area was 1.6-fold larger than that of control with SF treatment of $0.1 \mu \mathrm{g} / \mathrm{mL}$ and $0.5 \mu \mathrm{g} / \mathrm{mL}$ at 8 days after differentiation (Figure $1 \mathrm{C}$ and $\mathrm{D}$ ). Concentrations $>1 \mu \mathrm{g} / \mathrm{mL}$ caused rather reduced differentiation effects at day 8 , supposedly by toxic effect. We chose SF concentration of $0.5 \mu \mathrm{g} / \mathrm{mL}$, which showed the best result on differentiation, to be used on the subsequent experiment of HSkMCs.

\section{SF increased phosphorylation of P70S6K and 4E-BPI through mTOR signaling}

To identify signaling pathways that were involved in SF-enhanced differentiation, HSkMCs were seeded on a Q100 $\mathrm{mm}$ dish $\left(1 \times 10^{6} \mathrm{cells} / \mathrm{plate}\right)$, and the next day, they were treated with SF of $0.5 \mu \mathrm{g} / \mathrm{mL}$ in DM. At 1 day, 2 days, and 4 days after differentiation, the cells were harvested and lysed. We observed that SF increased phosphorylation of mTOR compared with control on the first day (Figure 2A and B). Levels of p-mTOR were normalized to the levels of GAPDH, as it has been suggested that myogenesis is affected by mTOR expression in kinase-independent way. ${ }^{48}$ This increase significantly upregulated the phosphorylation of P70S6K and 4E-BP1 (Figure 2C and D). p-P70S6K exhibited upregulation also in the late phase (day 4) of differentiation (Figure 2C). We concluded that SF induces muscle hypertrophy by protein synthesis through $\mathrm{mTOR} / \mathrm{P} 70 \mathrm{~S} 6 \mathrm{~K}$ and 4E-BP1 signaling in HSkMCs.

\section{SF inhibited muscle atrophy through increasing protein synthesis}

DEX is a glucocorticoid that mediates muscle proteolysis. ${ }^{19,21,35,46}$ Atrophy of myotubes was induced by $100 \mu \mathrm{M}$ DEX. HSkMCs were treated with SF of $0.5 \mu \mathrm{g} / \mathrm{mL}$ in DM and changed to fresh DM and SF every 2 days. At 2 days after induction of differentiation, cells were incubated with 

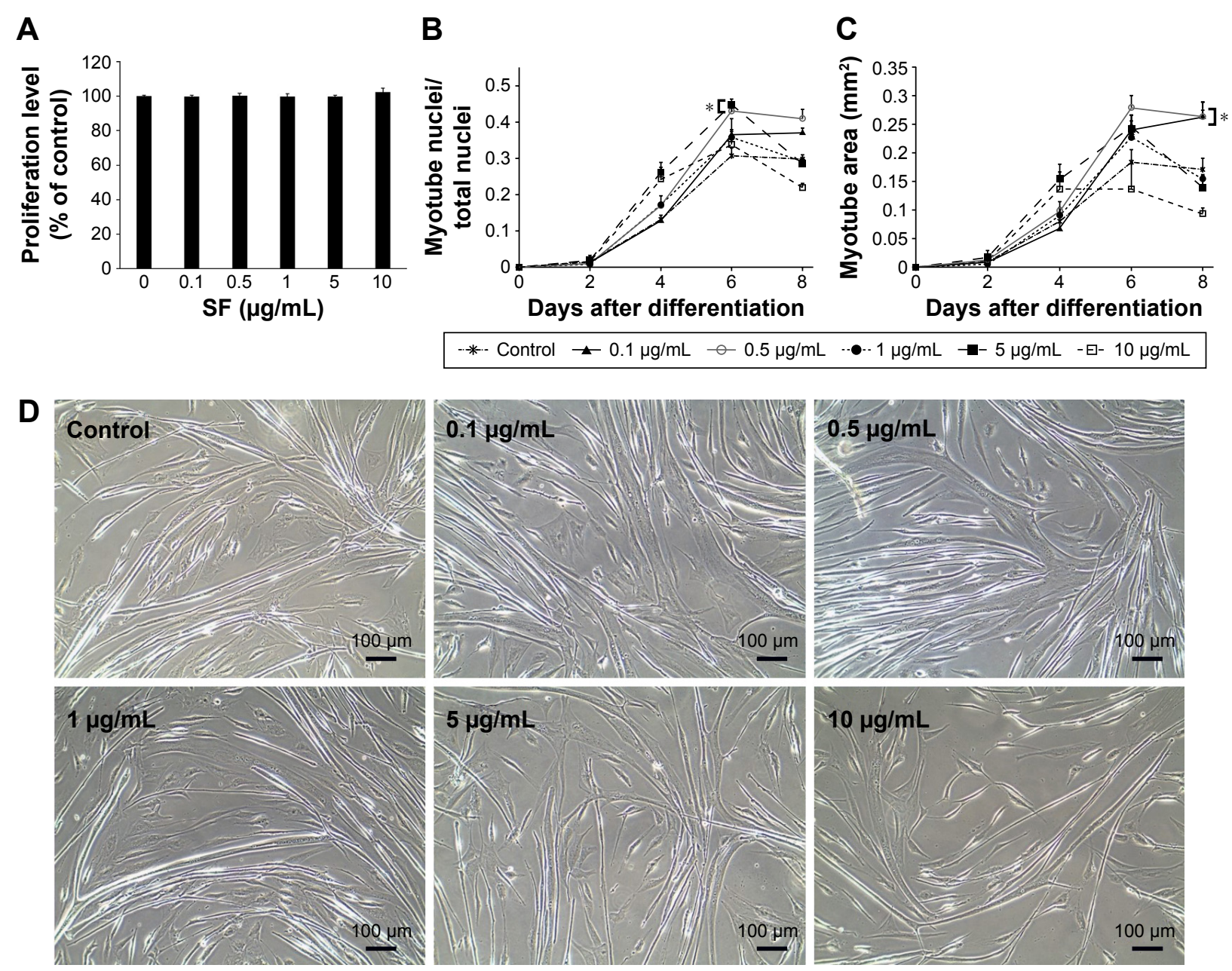

Figure I SF-induced differentiation in HSkMCs.

Notes: (A) SF was treated with various concentrations $(0.1 \mu \mathrm{g} / \mathrm{mL}, 0.5 \mu \mathrm{g} / \mathrm{mL}, I \mu \mathrm{g} / \mathrm{mL}, 5 \mu \mathrm{g} / \mathrm{mL}$, and $10 \mu \mathrm{g} / \mathrm{mL})$ in growth medium. Two days after treatment, HSkMCs were counted. As a result, SF did not induce proliferation. (B and C) SF $(0.1 \mu \mathrm{g} / \mathrm{mL}, 0.5 \mu \mathrm{g} / \mathrm{mL}, I \mu \mathrm{g} / \mathrm{mL}, 5 \mu \mathrm{g} / \mathrm{mL}$, and I0 $\mu \mathrm{g} / \mathrm{mL})$ was treated with DM and changed with fresh DM every 2 days. HSkMCs were photographed three times every 2 days. For observing differentiation efficiency, fusion index and myotube area were analyzed. (D) Eight days after differentiation induction with SF, HSkMCs were photographed. A total of $0.5 \mu \mathrm{g} / \mathrm{mL}$ of SF significantly induced more differentiation. All data represented mean \pm SEM $(n=3)$. *Symbol indicates $P<0.05$ compared to control.

Abbreviations: DM, differentiation medium; HSkMCs, human skeletal muscle cells; SF, Schisandrae fructus.

$100 \mu \mathrm{M}$ DEX for 4 days to induce atrophy. In the last 6 days after induction of differentiation, we could see that DEX treatment inhibits differentiation by fusion index and myotube area (Figure 3A-C) and MYH3 expression (Figure 3D and $\mathrm{E})$. Those cells that induced atrophy were attenuated by SF treatment in concert with the upregulation of p-4E-BP1 and p-P70S6K (Figure 3E). However, SF did not inhibit the increase in MuRF1, which is responsible for muscle protein degradation through ubiquitin-proteasome pathway, induced by DEX (Figure 3F). Finally, differentiation enhancement by SF was revealed by MYH expression, a late-phase marker of myotube differentiation (Figure 3D and E). By these data, we could see that SF suppresses muscle atrophy by inducing protein synthesis in human myotubes.

\section{Discussion}

Muscle mass is frequently compromised by aging. ${ }^{1-5}$ Search for the dietary supplements to ameliorate and maintain skeletal muscle function is becoming an important topic in antiaging research field. ${ }^{49-55}$

Muscle growth starts by the activation of quiescent myoblasts (proliferation). These cells get committed to myogenic differentiation and fuse with existing muscle fibers. ${ }^{56-61}$ In vivo skeletal muscle growth is identified by hypertrophy (increase in fiber size) and hyperplasia (increase in fiber number), ${ }^{62-64}$ while in vitro myogenic differentiation can be quantified by fusion index (ratio of fused nucleus) and area (hypertrophy) of myotubes. ${ }^{42,43}$ In addition, maintenance of myotubes is influenced by signals of skeletal muscle protein 
A

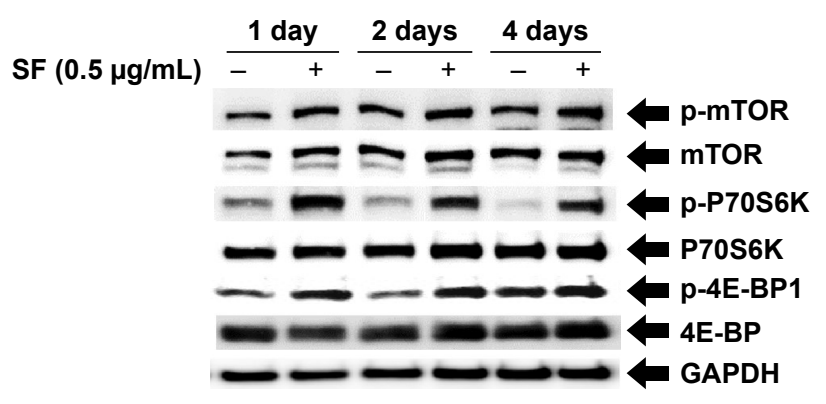

C

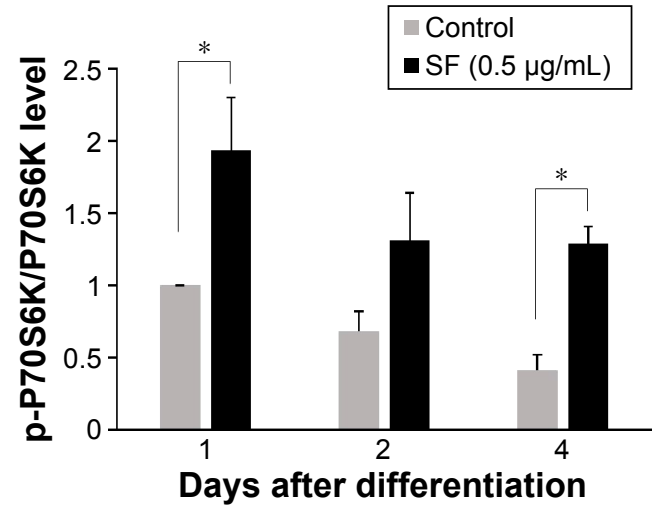

B
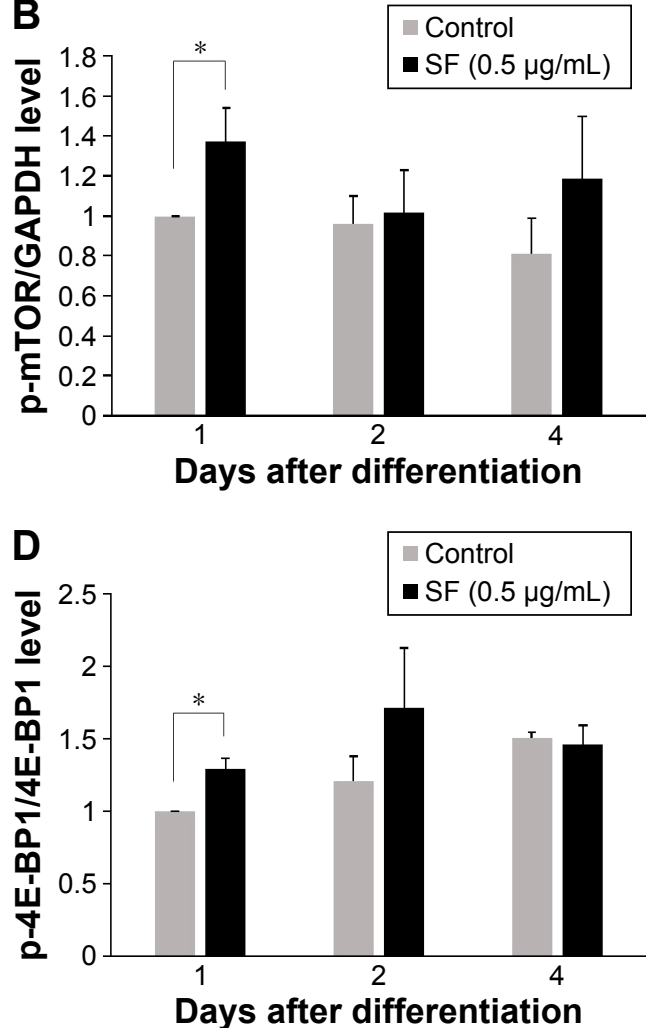

Figure 2 SF increased protein synthesis through mTOR/P70S6K and 4E-BPI signaling.

Notes: (A) SF $(0.5 \mu \mathrm{g} / \mathrm{mL})$ was treated with differentiation medium. HSkMCs' differentiation was induced for I day, 2 days, and 4 days. Phosphorylation and expression of mTOR, P70S6K, and 4E-BPI were observed for Western blot. GAPDH expression was analyzed to identify equal loading. (B-D) Levels of $m$ TOR activation (phosphorylation) were normalized to the levels of GAPDH. ${ }^{48}$ Phosphorylation of P70S6K and 4E-BPI was normalized to the levels of each total protein. All data represented mean \pm SEM $(n=3)$. *Symbol indicates $P<0.05$.

Abbreviations: 4E-BPI, 4E-binding protein I; HSkMCs, human skeletal muscle cells; mTOR, mammalian target of rapamycin; p-4E-BPI, phosphorylated 4E-BPI; P-P70S6K, phosphorylated P70S6K; P70S6K, 70 kDa ribosomal protein S6 kinase; SF, Schisandrae fructus; SEM, standard error of mean; GAPDH, glyceraldehyde 3-phosphate dehydrogenase.

synthesis and degradation. ${ }^{25}$ So we investigated which signals regulate differentiation by SF treatment. Various concentrations of SF were treated with HSkMCs with growth medium and DM, while SF did not significantly affect HSkMCs under proliferation (Figure 1A), but $0.5 \mu \mathrm{g} / \mathrm{mL}$ of SF could remarkably increase differentiation at 6 days by fusion index and at 8 days by myotube area after differentiation (Figure 1B-D).

According to the previous studies, many kinds of materials, such as ursolic acid and leucine,,$^{26,32,37,51}$ as well as exercise that have been known to induce skeletal muscle hypertrophy are associated with mTOR and transforming growth factorbeta signaling. ${ }^{21,26,27} \mathrm{SF}$ also activated signaling pathway of mTOR/p-P70S6K and p-4E-BP1 in early phases of differentiation (Figure 2). This activated signaling increased the synthesis of skeletal muscle proteins (Figure 3D and E). However, SF did not reduce MuRF1, which is responsible for muscle protein degradation through ubiquitin-proteasome pathway (Figure 3F). Nevertheless, we could observe substantial myotube hypertrophy by SF treatment showing increase in fusion index and myotube area and MYH expression in human myotubes (Figures 1 and 3).

Much research has utilized DEX-treated mice and C2C12 to generate muscle atrophy. ${ }^{19,21,47}$ In this study, DEX provoked atrophic changes accompanied by increase in MuRF1 expression.

The upstream p-FOXO1 increased on the application of SF, which links to the inhibition of the protein degradation (Figure S2). However, contrary to the previous report with DEX-treated mice, ${ }^{21} \mathrm{SF}$ treatment did not attenuate MuRF1 expression but rather raised it (Figure 3F). We speculate that MuRF1 expression by SF might be associated with FOXO3 levels or activity. Nevertheless, MYH expression and P70S6K activation were restored by SF inducing differentiation (Figure 3D and E). We suppose that this SF-induced muscle hypertrophy is influenced by the activation of mTOR signaling and the resultant increased protein synthesis than the inhibition of MuRF1 (Figure 4). It is still 
A

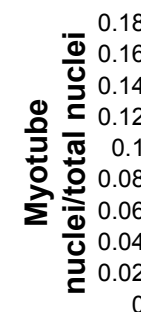

DEX $(100 \mu \mathrm{M})$

SF $(0.5 \mu \mathrm{g} / \mathrm{mL})$

C

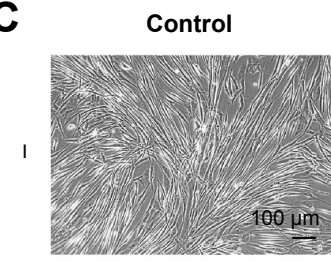

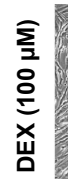

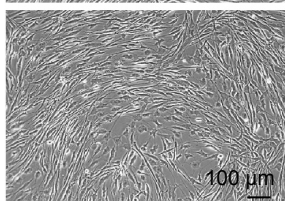

E

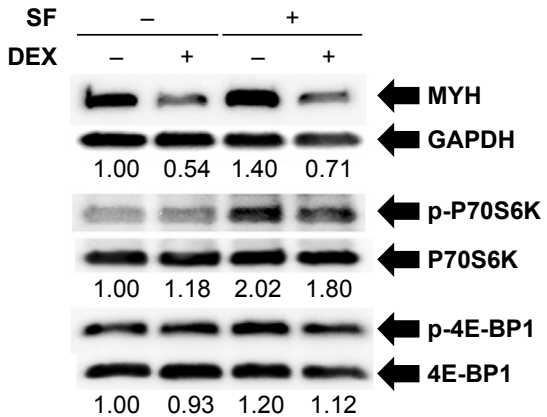

B

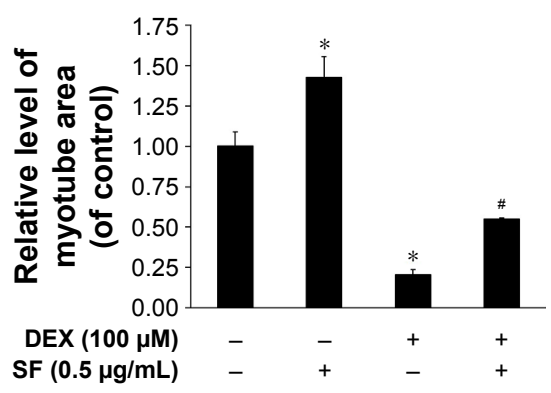

D

Control

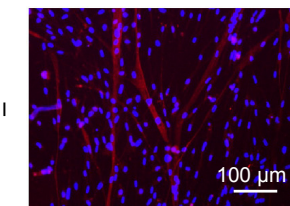

SF $(0.5 \mu \mathrm{g} / \mathrm{mL})$
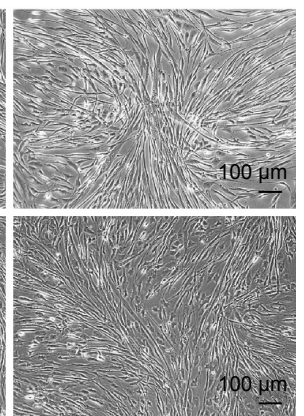

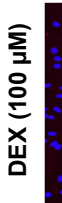

F

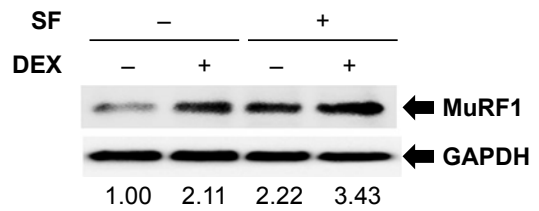

Figure $3 \mathrm{SF}$ inhibited muscle atrophy through increasing protein synthesis.

Notes: At 2 days of differentiation, atrophy of myotubes was induced by $100 \mu$ M DEX for 4 days, and DM was changed to fresh DM with SF every 2 days. (A-C) In the last 6 days after induction of differentiation, HSkMCs were photographed three times per group. For observing differentiation efficiency, fusion index and myotube area were analyzed. All data represented mean \pm SEM $(n=3)$. *Symbol indicates $P<0.05$ compared to control. \#Symbol represents $P<0.05$ compared to $D E X$ treatment alone. (D) Myotubes were fluorescence stained with anti-MYH (red) and DAPI (blue), which was observed as a marker of late differentiation. (E and F) Examples of representative Western blot were shown for MYH, p-P70S6K, P70S6K p-4E-BPI, 4E-BPI, GAPDH, and MuRFI. Levels of MYH, MuRFI, p-P70S6K, and p-4E-BPI were normalized to the levels of GAPDH or total protein.

Abbreviations: DEX, dexamethasone; DM, differentiation medium; 4E-BPI, 4E-binding protein I; HSkMCs, human skeletal muscle cells; MuRFI, muscle RING finger I; MYH, myosin heavy chain; P-4E-BPI, phosphorylated eukaryotic translation initiation factor 4E-binding protein I; p-P70S6K, phosphorylated P70S6K; P70S6K, 70 kDa ribosomal protein S6 kinase; SF, Schisandrae fructus; SEM, standard error of mean; GAPDH, glyceraldehyde 3-phosphate dehydrogenase.

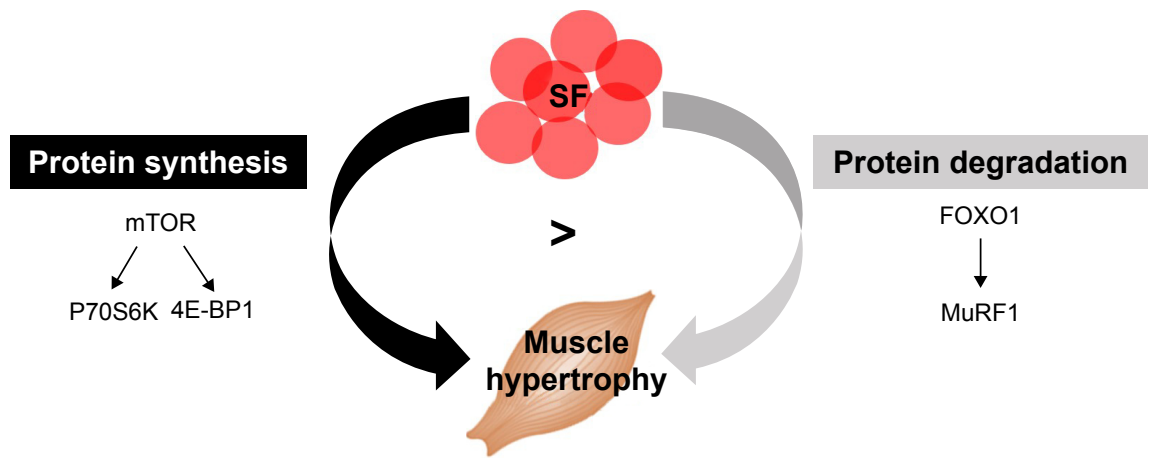

Figure 4 The diagram describes the mechanism of SF that increases muscle hypertrophy.

Notes: It is suggested that SF increased protein degradation through increasing MuRFI expression; nevertheless, it could also increase muscle hypertrophy by inducing myogenic differentiation and attenuating atrophy by protein synthesis through mTOR/P70S6K and 4E-BPI signaling pathway.

Abbreviations: 4E-BPI, 4E-binding protein I; mTOR, mammalian target of rapamycin; MuRFI, muscle RING finger I; P70S6K, 70 kDa ribosomal protein S6 kinase; $\mathrm{SF}$, Schisandrae fructus. 
probable that application of DEX early in the differentiation posed antidifferentiation effect, which was alleviated by SF extract to result in myotube hypertrophy.

\section{Conclusion}

SF could enhance myogenic differentiation and attenuate atrophy in human myotubes, supporting previous reports from mouse models. We confirmed that these effects are mediated by increased protein synthesis through mTOR/ P70S6K/4E-BP1 signaling pathway (Figure 4). We find that the human myotube culture is a good testbed to screen materials to benefit human skeletal muscle, which may reveal aspects different from those by mice experiment. It will eventually help the people with sarcopenia or myopathy to maintain and strengthen their skeletal muscle.

\section{Acknowledgment}

This study was supported by the R\&D program of MOTIE/ KEIT (10040391; Development of Functional Food Materials and Device for Prevention of Aging-associated Muscle Function Decrease).

\section{Disclosure}

The authors report no conflicts of interest in this work.

\section{References}

1. Moulias R, Meaume S, Raynaud-Simon A. Sarcopenia, hypermetabolism, and aging. Z Gerontol Geriatr. 1999;32(6):425-432.

2. Doherty TJ. Invited review: aging and sarcopenia. J Appl Physiol (1985). 2003;95(4):1717-1727.

3. Choi KM. Sarcopenia and sarcopenic obesity. Endocrinol Metab (Seoul). 2013;28(2):86-89.

4. Ali S, Garcia JM. Sarcopenia, cachexia and aging: diagnosis, mechanisms and therapeutic options - a mini-review. Gerontology. 2014;60(4): 294-305.

5. Siparsky PN, Kirkendall DT, Garrett WE Jr. Muscle changes in aging: understanding sarcopenia. Sports Health. 2014;6(1):36-40.

6. Kim YS, Lee Y, Chung YS, et al. Prevalence of sarcopenia and sarcopenic obesity in the Korean population based on the Fourth Korean National Health and Nutritional Examination Surveys. J Gerontol A Biol Sci Med Sci. 2012;67(10):1107-1113.

7. Arai $\mathrm{H}$, Akishita $\mathrm{M}$, Chen LK. Growing research on sarcopenia in Asia. Geriatr Gerontol Int. 2014;14(suppl 1):1-7.

8. Chen LK, Liu LK, Woo J, et al. Sarcopenia in Asia: consensus report of the Asian Working Group for Sarcopenia. J Am Med Dir Assoc. 2014; 15(2):95-101.

9. Kwon HA, Kwon YJ, Kwon DY, Lee JH. Evaluation of antibacterial effects of a combination of coptidis rhizoma, mume fructus, and schizandrae fructus against Salmonella. Int J Food Microbiol. 2008;127(1-2): 180-183

10. Panossian A, Wikman G. Pharmacology of Schisandra chinensis Bail: an overview of Russian research and uses in medicine. $J$ Ethnopharmacol. 2008;118(2):183-212.

11. Xie W, Du L. Diabetes is an inflammatory disease: evidence from traditional Chinese medicines. Diabetes Obes Metab. 2011;13(4):289-301.

12. Chen X, Huang Y, Feng J, Jiang XF, Xiao WF, Chen XX. Antioxidant and anti-inflammatory effects of and extracts in the treatment of asthma. Exp Ther Med. 2014;8(5):1479-1483.
13. Bae H, Kim R, Kim Y, et al. Effects of Schisandra chinensis Baillon (Schizandraceae) on lipopolysaccharide induced lung inflammation in mice. J Ethnopharmacol. 2012;142(1):41-47.

14. Zhong S, Nie YC, Gan ZY, et al. Effects of Schisandra chinensis extracts on cough and pulmonary inflammation in a cough hypersensitivity guinea pig model induced by cigarette smoke exposure. J Ethnopharmacol. 2015;165:73-82.

15. Kang JS, Han MH, Kim GY, et al. Nrf2-mediated HO-1 induction contributes to antioxidant capacity of a Schisandrae Fructus ethanol extract in C2C12 myoblasts. Nutrients. 2014;6(12):5667-5678.

16. Huang L, Chen L, Zhang Z. [Pathological observations of Fructus Schisandrae polysaccharide on anti-tumor effects in S180-bearing mice]. Zhong Yao Cai. 2004;27(3):202-203. Chinese.

17. Jeong JW, Kim JW, Ku SK, et al. Essential oils purified from Schisandrae semen inhibits tumor necrosis factor-alpha-induced matrix metalloproteinase-9 activation and migration of human aortic smooth muscle cells. BMC Complement Altern Med. 2015;15:7.

18. Yip AY, Loo WT, Chow LW. Fructus Schisandrae (Wuweizi) containing compound in modulating human lymphatic system - a Phase I minimization clinical trial. Biomed Pharmacother. 2007;61(9):588-590.

19. Xu X, Zhou X, Zhou XW, et al. Schizandrin prevents dexamethasoneinduced cognitive deficits. Neurosci Bull. 2012;28(5):532-540.

20. Kang JS, Han MH, Kim GY, et al. Schisandrae semen essential oil attenuates oxidative stress-induced cell damage in $\mathrm{C} 2 \mathrm{C} 12$ murine skeletal muscle cells through Nrf2mediated upregulation of HO1. Int J Mol Med. 2015;35(2):453-459.

21. Kim JW, Ku SK, Han MH, et al. The administration of Fructus Schisandrae attenuates dexamethasone-induced muscle atrophy in mice. Int J Mol Med. 2015;36(1):29-42.

22. Kim JW, Ku SK, Kim KY, et al. Schisandrae Fructus supplementation ameliorates sciatic neurectomy-induced muscle atrophy in mice. Oxid Med Cell Longev. 2015;2015:872428.

23. Lee TH, Jung CH, Lee DH. Neuroprotective effects of Schisandrin B against transient focal cerebral ischemia in Sprague-Dawley rats. Food Chem Toxicol. 2012;50(12):4239-4245.

24. Kim YJ, Yoo SR, Chae CK, Jung UJ, Choi MS. Omija fruit extract improves endurance and energy metabolism by upregulating PGC-1alpha expression in the skeletal muscle of exercised rats. J Med Food. 2014; 17(1):28-35

25. Glass DJ. Skeletal muscle hypertrophy and atrophy signaling pathways. Int J Biochem Cell Biol. 2005;37(10):1974-1984.

26. Anthony JC, Yoshizawa F, Anthony TG, Vary TC, Jefferson LS, Kimball SR. Leucine stimulates translation initiation in skeletal muscle of postabsorptive rats via a rapamycin-sensitive pathway. J Nutr. 2000; 130(10):2413-2419.

27. Song YH, Godard M, Li Y, Richmond SR, Rosenthal N, Delafontaine P. Insulin-like growth factor I-mediated skeletal muscle hypertrophy is characterized by increased mTOR-P70S6K signaling without increased Akt phosphorylation. J Investig Med. 2005;53(3):135-142.

28. Esser K. Regulation of mTOR signaling in skeletal muscle hypertrophy. J Musculoskelet Neuronal Interact. 2008;8(4):338-339.

29. Rivas DA, Lessard SJ, Coffey VG. mTOR function in skeletal muscle: a focal point for overnutrition and exercise. Appl Physiol Nutr Metab. 2009;34(5):807-816.

30. Goodman CA, Miu MH, Frey JW, et al. A phosphatidylinositol 3-kinase/ protein kinase B-independent activation of mammalian target of rapamycin signaling is sufficient to induce skeletal muscle hypertrophy. Mol Biol Cell. 2010;21(18):3258-3268.

31. Ogasawara R, Sato K, Matsutani K, Nakazato K, Fujita S. The order of concurrent endurance and resistance exercise modifies mTOR signaling and protein synthesis in rat skeletal muscle. Am J Physiol Endocrinol Metab. 2014;306(10):E1155-E1162.

32. Kim M, Sung B, Kang YJ, et al. The combination of ursolic acid and leucine potentiates the differentiation of $\mathrm{C} 2 \mathrm{C} 12$ murine myoblasts through the mTOR signaling pathway. Int J Mol Med. 2015;35(3):755-762.

33. Clavel S, Coldefy AS, Kurkdjian E, Salles J, Margaritis I, Derijard B. Atrophyrelated ubiquitin ligases, atrogin-1 and MuRF1 are up-regulated in aged rat tibialis anterior muscle. Mech Ageing Dev. 2006;127(10):794-801. 
34. Edstrom E, Altun M, Hagglund M, Ulfhake B. Atrogin-1/MAFbx and MuRF1 are downregulated in aging-related loss of skeletal muscle. J Gerontol A Biol Sci Med Sci. 2006;61(7):663-674.

35. Clarke BA, Drujan D, Willis MS, et al. The E3 ligase MuRF1 degrades myosin heavy chain protein in dexamethasone-treated skeletal muscle. Cell Metab. 2007;6(5):376-385.

36. Polge $\mathrm{C}$, Heng AE, Jarzaguet M, et al. Muscle actin is polyubiquitinylated in vitro and in vivo and targeted for breakdown by the E3 ligase MuRF1. FASEB J. 2011;25(11):3790-3802.

37. Maki T, Yamamoto D, Nakanishi S, et al. Branched-chain amino acids reduce hindlimb suspension-induced muscle atrophy and protein levels of atrogin-1 and MuRF1 in rats. Nutr Res. 2012;32(9):676-683.

38. Bodine SC, Baehr LM. Skeletal muscle atrophy and the E3 ubiquitin ligases MuRF1 and MAFbx/atrogin-1. Am J Physiol Endocrinol Metab. 2014;307(6):E469-E484.

39. Baehr LM, Furlow JD, Bodine SC. Muscle sparing in muscle RING finger 1 null mice: response to synthetic glucocorticoids. JPhysiol. 2011; 589(pt 19):4759-4776.

40. Roques M, Vidal H. A phosphatidylinositol 3-Kinase/p70 ribosomal S6 protein kinase pathway is required for the regulation by insulin of the p85alpha regulatory subunit of phosphatidylinositol 3-kinase gene expression in human muscle cells. J Biol Chem. 1999;274(48): 34005-34010.

41. Bouzakri K, Roques M, Gual P, et al. Reduced activation of phosphatidylinositol-3 kinase and increased serine 636 phosphorylation of insulin receptor substrate- 1 in primary culture of skeletal muscle cells from patients with type 2 diabetes. Diabetes. 2003;52(6):1319-1325.

42. Velica P, Bunce CM. A quick, simple and unbiased method to quantify C2C12 myogenic differentiation. Muscle Nerve. 2011;44(3):366-370.

43. Wilson EM, Tureckova J, Rotwein P. Permissive roles of phosphatidyl inositol 3-kinase and Akt in skeletal myocyte maturation. Mol Biol Cell. 2004;15(2):497-505.

44. Alesci S, Manoli I, Michopoulos VJ, et al. Development of a human mitochondria-focused cDNA microarray (hMitChip) and validation in skeletal muscle cells: implications for pharmaco- and mitogenomics. Pharmacogenomics J. 2006;6(5):333-342.

45. Ma K, Mallidis C, Artaza J, Taylor W, Gonzalez-Cadavid N, Bhasin S. Characterization of 5'-regulatory region of human myostatin gene: regulation by dexamethasone in vitro. Am J Physiol Endocrinol Metab. 2001; 281(6):E1128-E1136.

46. Zhao W, Pan J, Zhao Z, Wu Y, Bauman WA, Cardozo CP. Testosterone protects against dexamethasone-induced muscle atrophy, protein degradation and MAFbx upregulation. J Steroid Biochem Mol Biol. 2008; 110(1-2):125-129.

47. Menconi M, Gonnella P, Petkova V, Lecker S, Hasselgren PO. Dexamethasone and corticosterone induce similar, but not identical, muscle wasting responses in cultured L6 and $\mathrm{C} 2 \mathrm{C} 12$ myotubes. J Cell Biochem. 2008;105(2):353-364.

48. Erbay E, Chen J. The mammalian target of rapamycin regulates C2C12 myogenesis via a kinase-independent mechanism. J Biol Chem. 2001;276(39):36079-36082.

49. Marcinek DJ, Conley KE. In vivo metabolic spectroscopy identifies deficits in mitochondrial quality and capacity in aging skeletal muscle. Clin Pharmacol Ther. 2014;96(6):669-671.
50. Rivas DA, Lessard SJ, Rice NP, et al. Diminished skeletal muscle microRNA expression with aging is associated with attenuated muscle plasticity and inhibition of IGF-1 signaling. FASEB J. 2014;28(9): 4133-4147.

51. Bakhtiari N, Hosseinkhani S, Tashakor A, Hemmati R. Ursolic acid ameliorates aging-metabolic phenotype through promoting of skeletal muscle rejuvenation. Med Hypotheses. 2015;85(1):1-6.

52. LiuHW, Chan YC,WangMF, WeiCC,ChangSJ.Dietary(-)-epigallocatechin3-gallate supplementation counteracts aging-associated skeletal muscle insulin resistance and fatty liver in senescence-accelerated mouse. J Agric Food Chem. 2015;63(38):8407-8417.

53. Papaconstantinou J, Wang CZ, Zhang M, et al. Attenuation of p38alpha MAPK stress response signaling delays the in vivo aging of skeletal muscle myofibers and progenitor cells. Aging (Albany NY). 2015;7(9): 718-733.

54. Pauly M, Chabi B, Favier FB, et al. Combined strategies for maintaining skeletal muscle mass and function in aging: myostatin inactivation and AICAR-associated oxidative metabolism induction. J Gerontol A Biol Sci Med Sci. 2015;70(9):1077-1087.

55. Sin TK, Yung BY, Siu PM. Modulation of SIRT1-Foxo1 signaling axis by resveratrol: implications in skeletal muscle aging and insulin resistance. Cell Physiol Biochem. 2015;35(2):541-552.

56. Galliano MF, Huet C, Frygelius J, Polgren A, Wewer UM, Engvall E. Binding of ADAM12, a marker of skeletal muscle regeneration, to the muscle-specific actin-binding protein, alpha-actinin-2, is required for myoblast fusion. J Biol Chem. 2000;275(18):13933-13939.

57. Hara M, Yuasa S, Shimoji K, et al. G-CSF influences mouse skeletal muscle development and regeneration by stimulating myoblast proliferation. J Exp Med. 2011;208(4):715-727.

58. Minetti GC, Feige JN, Rosenstiel A, et al. Galphai2 signaling promotes skeletal muscle hypertrophy, myoblast differentiation, and muscle regeneration. Sci Signal. 2011;4(201):ra80.

59. Lei H, Leong D, Smith LR, Barton ER. Matrix metalloproteinase 13 is a new contributor to skeletal muscle regeneration and critical for myoblast migration. Am J Physiol Cell Physiol. 2013;305(5):C529-C538.

60. Webster MT, Fan CM. c-MET regulates myoblast motility and myocyte fusion during adult skeletal muscle regeneration. PLoS One. 2013; 8(11):e81757.

61. Teng S, Stegner D, Chen Q, et al. Phospholipase D1 facilitates secondphase myoblast fusion and skeletal muscle regeneration. Mol Biol Cell. 2015;26(3):506-517.

62. Ge X, McFarlane C, Vajjala A, et al. Smad3 signaling is required for satellite cell function and myogenic differentiation of myoblasts. Cell Res. 2011;21(11):1591-1604.

63. McCarthy JJ, Mula J, Miyazaki M, et al. Effective fiber hypertrophy in satellite cell-depleted skeletal muscle. Development. 2011;138(17): 3657-3666.

64. Antonio J, Gonyea WJ. Progressive stretch overload of skeletal muscle results in hypertrophy before hyperplasia. J Appl Physiol (1985). 1993; 75(3):1263-1271. 


\section{Supplementary materials Immunofluorescent staining}

Primary cultured human skeletal muscle cells $\left(2 \times 10^{4}\right.$ cells/well $)$ were seeded on a cover glass in a 12 -well plate, which was coated with $1 \%$ gelatin. After 2 days, cells were washed with phosphate buffered saline (PBS) and fixed by 4\% paraformaldehyde. Then, cells were permeabilized with PBS containing $0.25 \%$ Triton X-100 (PBST) for 25 minutes. These cells were incubated in 2\% BSA for 30 minutes and then with PAX3 (ab180754; Abcam) or PAX7 (ab34360; Abcam) antibodies overnight at $4^{\circ} \mathrm{C}$. After washing with PBS, cells were incubated with fluorescent antirabbit IgG antibodies (Alexa 594 or Alexa 488; Thermo Fisher Scientific, Waltham, MA, USA) for 1 hour. Nuclei were stained by Hoechst 33342 (DAPI, $1 \mu \mathrm{g} / \mathrm{mL}$ ) for 3 minutes. All antibodies were diluted in PBST containing 1\% BSA. These cells were mounted on a glass slide. These results were recorded using fluorescence microscopy (Eclipse 80i; Nikon Corporation, Tokyo, Japan).
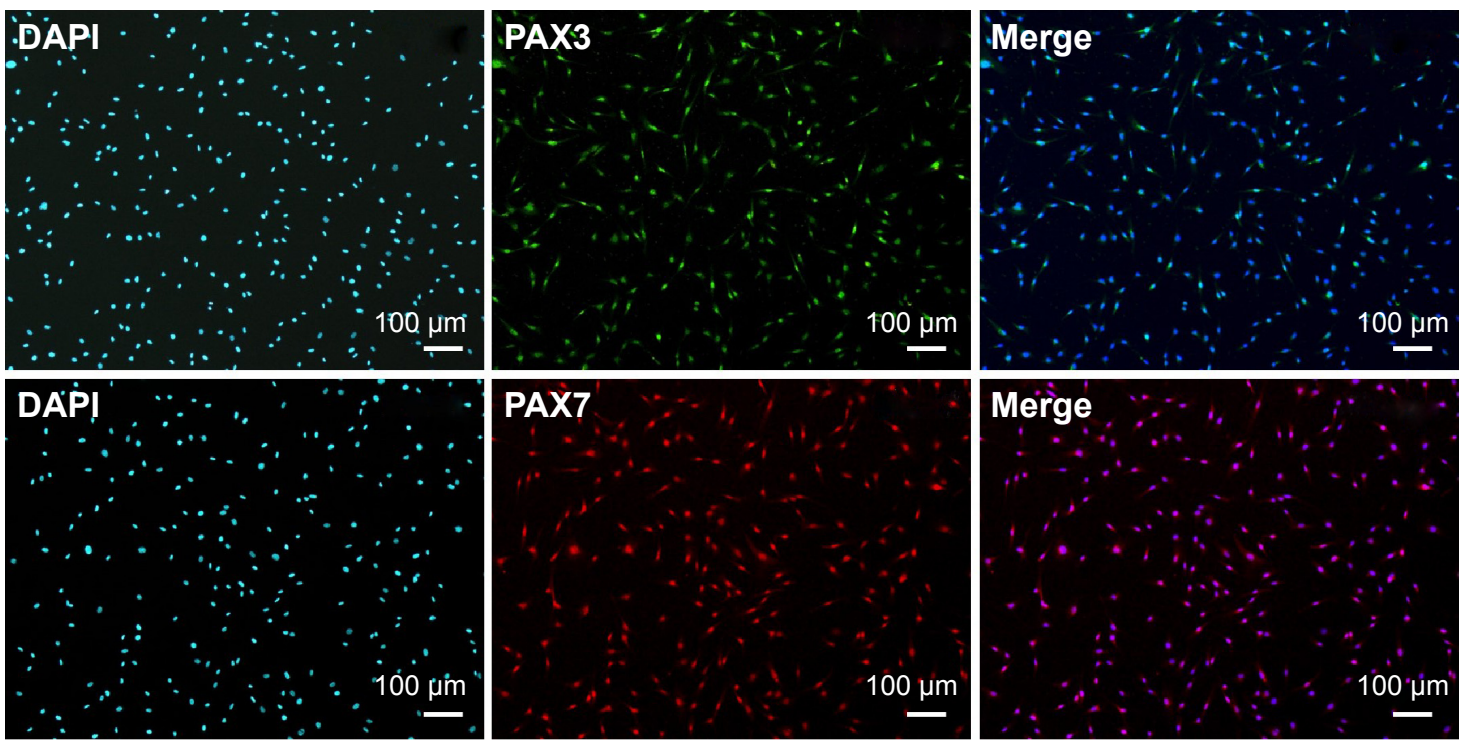

Figure SI Human skeletal muscle cells were identified by the expression of PAX3 and PAX7.

Notes: Primary cultured human skeletal muscle cells have exhibited the expression of PAX3 (green, upper panel) and PAX7 (red, lower panel), which have been known as human myoblast marker. Each of the stained cells was merged with nuclei.

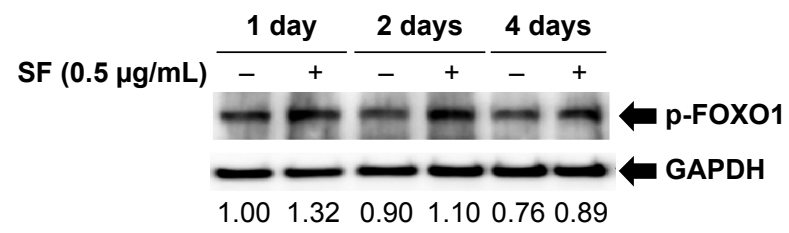

Figure S2 SF increased phosphorylation of FOXOI.

Notes: SF $(0.5 \mu \mathrm{g} / \mathrm{mL})$ was treated with differentiation medium. HSkMCs' differentiation was induced for I day, 2 days, and 4 days. Phosphorylation of FOXO I was observed by Western blot. p-FOXOI levels were normalized to the levels of GAPDH.

Abbreviations: HSkMCs, human skeletal muscle cells; SF, Schisandrae fructus; GAPDH, glyceraldehyde 3-phosphate dehydrogenase.

International Journal of Nanomedicine

\section{Publish your work in this journal}

The International Journal of Nanomedicine is an international, peerreviewed journal focusing on the application of nanotechnology in diagnostics, therapeutics, and drug delivery systems throughout the biomedical field. This journal is indexed on PubMed Central, MedLine, CAS, SciSearch ${ }^{\circledR}$, Current Contents ${ }^{\circledR} /$ Clinical Medicine,

\section{Dovepress}

Journal Citation Reports/Science Edition, EMBase, Scopus and the Elsevier Bibliographic databases. The manuscript management system is completely online and includes a very quick and fair peer-review system, which is all easy to use. Visit http://www.dovepress.com/ testimonials.php to read real quotes from published authors. 